OPEN ACCESS

Edited by:

Marshall Thomas Holland Oregon Health and Science University,

United States

Reviewed by:

Nicole C. R. McLaughlin,

Butler Hospital, United States

Sameer A. Sheth,

Baylor College of Medicine,

United States

*Correspondence:

Jin Woo Chang

jchang@yuhs.ac

Specialty section:

This article was submitted to

Neuroimaging and Stimulation,

a section of the journal

Frontiers in Psychiatry

Received: 12 December 2020

Accepted: 11 March 2021

Published: 06 April 2021

Citation:

Chang KW, Jung HH and Chang JW

(2021) Magnetic Resonance-Guided

Focused Ultrasound Surgery for

Obsessive-Compulsive Disorders:

Potential for use as a Novel Ablative

Surgical Technique.

Front. Psychiatry 12:640832.

doi: 10.3389/fpsyt.2021.640832

\section{Magnetic Resonance-Guided Focused Ultrasound Surgery for Obsessive-Compulsive Disorders: Potential for use as a Novel Ablative Surgical Technique}

\author{
Kyung Won Chang, Hyun Ho Jung and Jin Woo Chang* \\ Department of Neurosurgery \& Brain Research Institute, Yonsei University College of Medicine, Seoul, South Korea
}

Surgical treatment for psychiatric disorders, such as obsessive-compulsive disorder (OCD) and depression, using ablative techniques, such as cingulotomy and capsulotomy, have historically been controversial for a number of scientific, social, and ethical reasons. Recently, with the elucidation of anatomical and neurochemical substrates of brain function in healthy controls and patients with such disorders using various functional neuroimaging techniques, these criticisms are becoming less valid. Furthermore, by using new techniques, such as deep brain stimulation (DBS), and identifying more precise targets, beneficial effects and the lack of serious complications have been demonstrated in patients with psychiatric disorders. However, DBS also has many disadvantages. Currently, magnetic resonance-guided focused ultrasound surgery (MRgFUS) is used as a minimal-invasive surgical method for generating precisely placed focal thermal lesions in the brain. Here, we review surgical techniques and their potential complications, along with anterior limb of the internal capsule (ALIC) capsulotomy by radiofrequency lesioning and gamma knife radiosurgery, for the treatment of OCD and depression. We also discuss the limitations and technical issues related to ALIC capsulotomy with MRgFUS for medically refractory OCD and depression. Through this review we hope MRgFUS could be considered as a new treatment choice for refractory OCD.

Keywords: deep brain stimulation, gamma knife surgery, magnetic resonance-guided focused ultrasound, obsessive-compulsive disorder, psychosurgery

\section{INTRODUCTION}

Obsessive-compulsive disorder (OCD) is a mental disorder characterized by time-consuming, distressing obsessions and/or compulsions (1). Obsessions are repetitive and persistent thoughts, images, impulses, or urges that are intrusive and unwanted and are commonly associated with anxiety (1). Compulsions are repetitive behaviors or mental acts that the individual feels driven to perform, according to strict rules, in response to an obsession or to achieve a sense of "completeness." It is often accompanied by avoidance behavior (1).

Most patients experience a continuous symptom course, although there is a waxing and waning symptom pattern in up to $25 \%$ (2). However, symptom progression can be highly influenced by treatment. Individuals with OCD often have a poor quality of life, similar to individuals with 
schizophrenia (3). The burden of personal and socio-economic costs associated with OCD is also considerable (4). Nevertheless, the condition is often unrecognized, particularly because symptoms are often internally experienced rather than externally expressed, and patients may be unwilling to reveal thoughts or behaviors that they perceive as shameful or embarrassing (5). Consequently, the mean time from OCD symptom onset to initial pharmacological treatment is nearly 8 years (6). Among patients who receive clinical attention, $<40 \%$ receive OCDspecific therapy and $<10 \%$ receive evidence-based treatment (7).

The initial treatment for OCD involves pharmacological treatment or cognitive-behavioral therapy (CBT) $(1,5,8)$. Selective serotonin-reuptake inhibitors (SSRIs) are the first-line of pharmacological treatment for OCD, with proven efficacy in reducing OCD symptoms and tolerability demonstrated in multiple trials (9). However, approximately half of OCD patients treated with first-line treatment fail to show a complete response (10). Insufficient response after CBT or SSRI monotherapy can also be resolved by combination therapy $(5,8)$. For treatmentrefractory OCD, after failure of SSRI or combination therapy, alternative approaches could be considered. Neurosurgical techniques, focused on the lesioning of specific components of the neural circuits associated with OCD, have been used for decades to treat patients with severe, treatment-refractory symptoms (11-13). In this reviews, we provide an overview of the history of surgery for psychiatric disorders and discuss the latest surgical options for psychiatric disorders, with a focus on OCD. To our knowledge there are few review regarding MRgFUS as a treatment option for psychiatric disorders.

\section{BRIEF HISTORY OF PSYCHIATRIC NEUROSURGERY}

Surgery for psychiatric disorders includes techniques involving neuroablation and neuromodulation, such as stimulation techniques. Psychiatric neurosurgery has a long history of controversy for various scientific, social, and ethical reasons. Throughout the 1800s, new knowledge regarding functional neuroanatomy and neurophysiology sparked an interest in psychiatric neurosurgery (14). In 1819, Franz Joseph Gall published his thesis on phrenology, suggesting that the brain has distinct functional areas (15). Although the concept of phrenology was defective and was eventually discounted, the idea of neurological functions having an anatomical correlation was expanded on by the seminal work on the localization of language function by Paul Broca and Carl Wernicke, followed by further research by Gustav Fritsch, Eduard Hitzig, and David Ferrier on the localization of the motor cortex (16). These findings inspired interest in psychiatric neurosurgery. In 1889, Gottlieb Burckhardt presented his operative findings and outcomes at the Berlin Medical Congress (17). In six patients with various psychiatric disorders, he conducted selective removal of the left frontotemporal cerebral cortex. In three of these cases, Burckhardt claimed to achieve success in treatment, but his eccentric research was deeply criticized by the international medical community when he published his surgical results in 1891, leading to discontinuation of the project. Research on and practice of psychiatric neurosurgery stagnated until 1935, when a primate model study by John Fulton and Carlyle Jacobsen described the frontal lobe's role in short term memory, anxiety, and aggression (14). This study encouraged Egas Moniz and Almeida Lima to perform the first prefrontal leucotomies in 20 psychiatric patients with schizophrenia, bipolar disorder, and anxiety disorders (18). Walter Freeman and James Watts modified the technique and began to perform modified lobotomies in $1936(14,17,19)$, which became popular worldwide. By 1949, an estimated 10,000 lobotomies had been performed in the US and Europe. Moniz won the 1949 Nobel Prize for medicine for the discovery of the role of prefrontal leucotomy in the treatment of certain psychoses (17).

Nevertheless, eventually both professional and public opinion turned against lobotomy, as the procedure was regarded as unethical and unscientific. Additionally, the associated morbidity and mortality, the so called "post-leucotomy syndrome," became more evident $(14,20)$. To reduce the morbidity and mortality, a more selective approach was considered, and improvements were attained with advances in stereotactic neurosurgery. In 1949, Talairach announced the use of a stereotactic frame to coagulate the frontothalamic fibers in the ALIC selectively, at the 4th International Congress of Neurology in Paris (17). Thereafter, stereotactic psychiatric neurosurgery rapidly replaced prefrontal lobotomy and was applied for various psychiatric disorders (21): cingulotomy for addiction, bipolar disorder, depression, OCD, schizoaffective disorder, and schizophrenia; anterior capsulotomy for general anxiety disorder and OCD; subcaudate tractotomy for depression, OCD, and schizophrenia; anterior callosotomy for schizoaffective disorder and schizophrenia; amygdalotomy for aggressive behavior associated with mental impairment; thalamotomy for Tourette syndrome and hypothalamotomy for addiction, aggression, and sexual disorders.

In the 1950s and 1960s, the use of psychiatric neurosurgery declined, and the number of patients requiring stereotactic psychiatric neurosurgery was markedly reduced $(22,23)$. This can be ascribed to multiple factors, such as social attitudes and ethical problems, as well as the introduction of psychoactive drugs, such as chlorpromazine, reserpine, lithium, haloperidol, imipramine, and diazepam. The development and approval of other antipsychotics and antidepressants soon followed, and there was evidence that medical therapy was more effective, safer, and cheaper than psychiatric neurosurgery (14).

Although there was controversy surrounding the evolution of psychiatric neurosurgery, it was instrumental in the development of modern standards of research and ethics, with the passing of the National Research Act of 1974 and subsequent publication of the Belmont Report (14). The 1977 US National Commission Report on Psychiatric Neurosurgery claims "The Commission affirms that the use of psychosurgery for any purpose other than to provide treatment to individual patients would be inappropriate and should be prohibited. Accordingly, the Commission is recommending safeguards that should prevent the performance of psychosurgery for purposes of social or institutional control or other such misuse." (24). 


\section{VARIOUS NEUROABLATIVE PROCEDURES FOR OBSESSIVE-COMPULSIVE DISORDER}

Various neuroablative surgeries have been performed for OCD. Each surgery is named for its target, such as capsulotomy targeting the internal capsule, cingulotomy targeting the anterior cingulate cortex, and subcaudate tractotomy targeting the subcaudate white matter. Limbic leucotomy involves a combination of the latter two procedures $(5,12,21)$. The concept underlying ablative surgery for OCD is based on the pathological hyperactivity and dysfunctional connectivity in the limbic cortico-striato-thalamo-cortical (CSTC) loop (25).

Currently, the ablative methods used most commonly are radiofrequency and radiosurgical ablation, as well as the novel magnetic resonance-guided focused ultrasound surgery (MRgFUS) (21, 26-30). Approximately 30-60\% of patients with intractable OCD may experience significantly reduced OCD symptoms post-operatively (1). However, only gamma ventral capsulotomy has been studied in a double-blind, sham-controlled randomized trial (31). Using the response criteria [a 35\% reduction in the baseline Yale-Brown Obsessive Compulsive Scale (Y-BOCS) score plus a Clinical Global Impression change score of 1 or 2], the primary outcome measure did not reach statistical significance after 12 months, although the Y-BOCS score reduction over that same follow-up period was significantly greater in the active treatment group. At the end of the followup period (54 months), 7 of 12 (58\%) patients who underwent radiosurgery were deemed responders.

\section{Cingulotomy}

The anterior cingulate cortex is a region in the medial prefrontal cortex that surrounds the rostral corpus callosum. This region seems to have emotional and cognitive functions. Both functional roles make the anterior cingulate cortex a theoretically ideal focus for therapeutic intervention in psychiatric disorders in which these processes are impaired (25).

After Egas Moniz announced his first prefrontal leucotomy in 1936, thousands of patients with mental disorders underwent frontal lobar surgery until the 1950s (32), with modifications introduced by Walter Freeman and James Watts (19). However, because of the lack of anatomical precision of frontal leucotomy and the emergence of side effects, more restricted surgeries, such as frontal topectomy or undercutting under direct visualization or by electrocoagulation, were developed (33). After the stimulation of Brodmann area 24 in monkeys showed autonomic changes in emotional expression and a widespread cortical suppressor effect (34), bilateral removal of the anterior part of the cingular gyrus, i.e., anterior cingulotomy, was performed by Whitty et al. (35). Among the 24 patients in their series, four OCD patients showed significant improvements. Subsequently, in 1962, Foltz and White reported that stereotaxic cingulotomy in patients with intractable pain also improved their anxiety or depression (36). With these impressive results, Ballantine et al. performed bilateral stereotaxic cingulotomy for 57 patients with mental disorders (32) in 1967, and showed variable improvements in 30 patients. In 1972, Laitinen et al. used a stereotaxic frame for cingulotomy (37), and in 1990, radiofrequency was first used by Hassenbusch et al. (38). According to Ballantine et al.'s large study in 1987 (39), more than 400 OCD patients underwent bilateral stereotactic cingulotomy. The reported overall success rate was $30-40 \%$, with no other major side effects, but some minor complications were identified, such as persistent headache, nightmares, decreased libido, weight gain, and urinary incontinence. Adverse effects after cingulotomy have been reported as transient to mild symptoms, such as urinary symptoms (14\%), as well as permanent to serious symptoms, such as epilepsy or cognitive changes (5.2\%) (40).

In our institute's series regarding cingulotomy for OCD (28, 41), 17 patients had a Y-BOCS score of $35.0 \pm 3.86$ preoperatively and showed a mean improvement of $48 \%$ over the baseline score after a follow-up period of at least 2 years. A neuropsychological examination was performed in all of our patients to investigate whether there were any differences in cognitive function at 24 months after cingulotomy. No significant adverse effects were observed after the surgery. In a recent long-term study with a 5 -year mean follow-up period in 64 patients, Sheth et al. (42) showed a $47 \%$ rate of full response (more than $35 \%$ improvement in the Y-BOCS score).

\section{Capsulotomy}

Disruption of the ALIC is thought to yield efficacious or therapeutic relief in some psychiatric disorders, and some studies have demonstrated orbitofrontal cortex and subgenual cingulate projections leading to the medial thalamic nucleus. In 1949, Talairach first introduced the technique of anterior capsulotomy to disconnect fibers from the orbitofrontal cortex leading to the limbic system that pass through the ALIC for patients with psychiatric disorders (17). In the 1950s, Leksell and Talairach modernized anterior capsulotomy (43). In 1953, the first radiosurgical capsulotomy was performed with 300$\mathrm{kV}$ X-rays (44). Lippitz et al. reported 22 cases of bilateral thermo-capsulotomy from 1976 to 1989 , with a median followup period of 8.4 years; beneficial results were seen in $47 \%$ of cases (45). Bilateral thermo-capsulotomy results from a recent large study were reported by numerous studies. The rate of improvement in Y-BOCS scores was $43.3 \%$ according to Oliver et al. $(n=10)(46), 80.9 \%$ according to Liu et al. $(n=$ 35) (47), and $31.4 \%$ according to D'Astous et al. $(n=19)$ (48). The adverse effects after capsulotomy were reported as transient to mild in $56.2 \%$ of patients and as permanent to serious in $21.4 \%$ of patients in another study (40). Leksell introduced capsulotomy via gamma knife radiosurgery in 1955 (44). Improvements after gamma knife anterior capsulotomy were observed in $55-70 \%$ of patients. However, anatomical target localization, dose, and collimator selection varied among reports (44). Rück et al. in their series, compared thermo-capsulotomy and gamma capsulotomy (49) and found some side effects, such as apathy, incontinence, seizure, and executive dysfunction; they also reported that a very high radiation dose or multiple procedures should be avoided. Additionally, larger targets using an 8-mm collimator showed adverse radiation effects (50). 
Gamma capsulotomy has a risk of adverse radiation effects, such as radiation necrosis or brain edema or cyst formation (49). Worldwide, more than 240 cases of gamma capsulotomy were performed, and if the maximal dose was reduced below $180 \mathrm{~Gy}$, the number of adverse effects decreased (51). In a recent double-blind, randomized controlled trial by Lopes et al., 58.3\% (7/12) of cases were deemed responders after gamma ventral capsulotomy (31). Recently, in a large study of capsulotomy by Rasmussen et al. (52) 31 out of 55 patients had an improvement in the Y-BOCS score in a primary measure, and over $35 \%$ improvement in 3-year follow-up period. Patients had significant improvements in depression, anxiety, quality of life, and global functioning without significant acute adverse effects, only 5\% patients developed radio-necrotic cysts in long term followup. As the capsulotomy procedure have advanced, the adverse events have decreased significantly, with a remaining favorable treatment response of $\sim 50 \sim 66 \%$ of patients which were treated at experienced centers (53). The reduction in the severity of OCD may also result from improved efficacy of pharmacological and psychological treatments that work synergistically with capsulotomy as well as direct modulation of the OCD neural pathways (53).

\section{Limbic Leukotomy}

Limbic leucotomy is a combination of anterior cingulotomy and capsulotomy or subcaudate tractotomy. Kelly et al. (54) performed limbic leucotomies starting in the 1970s, with proven efficacy for mood disorders and OCD. Depending on the clinical symptoms, limbic leucotomy can be performed as a one-stage procedure (55), in which frontothalamic white matter tracts of the basal medial frontal lobes are lesioned, along with lesioning in anterior cingulate cortex. Alternatively, it can be performed in a two-stage procedure involving initial anterior cingulotomy, followed by subcaudate tractotomy (56). In a 7-year prospective study of patients with intractable bipolar disorder, one-stage limbic leucotomy yielded a significant reduction in depressive symptoms but not in manic symptoms (57). One group who performed a two-stage procedure showed a $73 \%$ symptom improvement rate in patients with OCD and intractable major depressive disorder who did not initially respond to anterior cingulotomy alone (56). The side effects of limbic leucotomy appear to be transient and to resolve spontaneously; they include transient hallucinations, amnesia, and mania (42). In particular, however, abulia appears to develop at a higher rate following limbic leucotomy than following cingulotomy, but it is still typically self-limiting (57).

\section{NEUROMODULATIVE SURGERY-DEEP BRAIN STIMULATION FOR OBSESSIVE-COMPULSIVE DISORDER}

DBS is an adjustable, reversible, and non-destructive procedure that has been proven to be safe for treating movement disorders. With DBS, surgically implanted electrodes deliver controlled electrical pulses to targeted areas of the brain, which activate adjacent neural circuits (58). The settings of the stimulation can be changed, and the electrodes can be removed from the brain. Compared to ablative neurosurgery, DBS has the advantages of being reversible and adjustable. Thus, there has been a trend for replacement of ablation techniques by DBS.

Significant advances in neuroscience and neuroimaging have resulted in the discovery of some circuits in the brain (59), and the application of DBS has increased with the greater understanding of the pathophysiology of psychiatric disorders.

DBS is reserved for highly refractory OCD cases, i.e., $<\sim 1 \%$ of patients (60). Approximately $30-50 \%$ of patients with severe refractory OCD respond to these alternative treatments $(13,61)$.

DBS has been attempted using various targets. Most studies on DBS have targeted striatal areas, including the ALIC, ventral capsule (VC), ventral striatum (VS), nucleus accumbens or the ventral caudate nucleus, subthalamic nucleus, and inferior thalamic peduncle $(1,13,62,63)$. Preliminary studies have also described the potential benefit of non-striatal targets, such as the superolateral branch of the medial forebrain bundle (64).

DBS was initially applied in the ALIC by Nuttin et al. (65), and reported DBS results for OCD: the mean preoperative Y-BOCS score of $32.3 \pm 3.9$ decreased to $19.8 \pm 8.0$ postoperatively, and the stimulation effect was maintained for at least 21 months after DBS. The effect of DBS in the internal capsule was limited and required high power, resulting in high battery consumption. Thus, the DBS target was gradually shifted more posteriorly where the anatomical sites were close to the VS, VC, nucleus accumbens, inferior thalamic peduncle, and bed nucleus of the stria terminalis $(66,67)$. Greenberg et al. (68) targeted the VC/VS where more compact fibers of the CSTC circuit course, slightly posterior to the target of standard capsulotomy. Additionally, the effects of DBS were more pronounced with posterior stimulation. The more posteriorly the electrode was positioned, the less energy (voltage and pulse width) was needed.

The nucleus accumbens plays a major role in modulating the CSTC circuit. Sturm et al. (62) designed a double-blind shamcontrolled crossover study with unilateral DBS for the nucleus accumbens. Five of 10 patients showed reduction of more than $25 \%$ over the baseline Y-BOCS score, and one patient showed a reduction of $>35 \%$ at 1 year post-operation. Another study on bilateral nucleus accumbens DBS in 16 patients by Denys et al. (69) reported 47 and 52\% reductions from the baseline Y-BOCS score after 12 and 21 months, respectively. Bilateral DBS in the inferior thalamic peduncle and in the limbic part of the subthalamic nucleus has also been reported, but the patients included were somewhat diverse and the sample size was small $(67,70)$.

Surgical risks still exist, and both lesioning and DBS pose a risk of hemorrhage, seizures, and infection. Although the risk of intracerebral hemorrhage is inevitable, the occurrence rates are low (1-2\% in large studies), irrespective of the symptoms (71). Additionally, the implantable pulse generator should be replaced when the battery is depleted. 


\section{NEW EMERGING TECHNIQUES-MAGNETIC RESONANCE-GUIDED FOCUSED ULTRASOUND SURGERY FOR OBSESSIVE-COMPULSIVE DISORDER}

Several experimental studies on focused ultrasound lesioning were conducted in the 1950s $(72,73)$. Owing to skull anatomy and the characteristics of ultrasound, focused ultrasound was only applied during craniotomy until the 1990s. The skull acts as a barrier and is a major obstacle against the penetration of ultrasound for making a focal lesion in the brain, and the heat from energy absorption can damage the scalp, bone, and adjacent brain parenchyma (74). The development of the phased array transducer and the introduction of MR thermometry made it possible to use transcranial MRgFUS as an ablative method (75). Unlike stereotactic radiofrequency procedures, which are irreversible, MRgFUS lesioning allows modification during the procedure since the thermal area can be monitored in realtime.

Transcranial MRgFUS is a minimally invasive and real-time monitoring procedure that has advantages over surgical techniques, such as radiosurgery, and other lesioning procedures (26). Intermittently examining the MR image or using MR thermometry during the sonication can confirm or predict the lesioning, and no ionizing radiation is involved. In addition, its precision and the feasibility of real-time monitoring during the procedure can minimize procedure-related complications (76). In addition, there are no other concerns about hardware implantation or replacement, or surgical morbidity, as with DBS. MRgFUS is a potentially more viable and cost-effective alternative to radiofrequency capsulotomy (26). Recently, MRgFUS has been widely applied for the treatment of various movement disorders (essential tremors, etc.), but there have been few studies involving psychiatric disorders. In our institute, MRgFUS for OCD has been done since our first study in 2013 (27).

\section{Patient Selection and Inclusion Criteria}

Patients who were diagnosed as treatment-refractory OCD were selected. All patients failed to respond to more than three SSRIs, including clomipramine, and more than one antipsychotic drug augmentation strategy (one or more SSRIs and one or more antipsychotics) and had OCD symptoms with psychosocial impairment for at least 5-years. Experienced psychiatrists conducted psychiatric interviews for diagnoses and assessment of symptoms or psychosocial functions. The inclusion criteria of the patients are: (1) a primary OCD diagnosis according to the Structured Clinical Interview of the Diagnostic and Statistical Manual of Mental Disorders; (2) at least a 3year history of OCD symptoms with psychosocial dysfunction (determined by a Global Assessment of Functioning Scale, score $\leqslant 50$ ); (3) a minimum score of 28 on the Yale-Brown ObsessiveCompulsive Scale (Y-BOCS); and (4) treatment refractory status, that is, non-responsive to pharmacological treatment (more than two types of serotonin reuptake inhibitors at the maximum tolerated dose for more than 12 weeks) and cognitive-behavioral therapy [a minimum of 20 sessions of primarily therapist-guided Exposure and Response Prevention (ERP)]. Previous medication (SSRIs or antipsychotics) were kept unchanged for at least 30 days before MRgFUS capsulotomy, and the regimen and dosage were maintained until the final assessment from the followup visit.

\section{MRgFUS Capsulotomy: Procedures \& Targeting}

MRgFUS capsulotomy was performed using a 3-T MR system (GE Medical Systems, Milwaukee, WI, USA) and the ExAblate 4,000 system (InSightec, Haifa, Israel) which features a $30-\mathrm{cm}$ diameter, hemispherical, 1,024 element phased-array transducer operating at $650 \mathrm{kHz}$. The patient's scalp is completely shaved and after the fixation of the Cosman-Roberts-Wells stereotactic frame, the patient is positioned to the ExAblate 4,000 system. A presonication MRI is performed and the images are fused with computed tomography, and other MR sequences are also evaluated to determine the target coordinates. The bilateral ALIC is targeted from the location $7-\mathrm{mm}$ anterior to the anterior margin of the anterior commissure in the level of AC-PC (Anterior Commissure-Posterior Commissure) plane, extending $2-3 \mathrm{~mm}$ along the internal capsule in the coronal view. Several subthreshold heatings with low-power sonications of $10 \mathrm{~s}$ durations were applied to induce peak temperatures of $40-42^{\circ} \mathrm{C}$. This low power sonication procedure is for safety which allows us to visualize the exact position and size of the thermal spot and to review the overall safety profile of the applied sonication parameters. After confirming the exact target, high-power sonication was then applied in a repetitive process guided by MRI and MR thermometry, with gradual increase in acoustic power and energy to achieve a peak temperature of 51$56^{\circ} \mathrm{C}$ in the target region for more than $3 \mathrm{~s}$. By adjusting the target coordinates, the goal is to create an $\sim 10$ - $\mathrm{mm}$ elliptical lesion in each side of the bilateral ALIC. During the procedure, particularly during cooling time, the patient is asked questions and examined by a neurosurgeon and a psychiatrist to observe whether there are notable physical or psychological changes. The patient is fully awake during the whole procedure and is monitored as an inpatient for $24 \mathrm{~h}$ after the procedure (Figure 1).

In study of treatment-refractory OCD in 11 patients who underwent MRgFUS in our institute (30), the Y-BOCS score decreased significantly over the 24-month follow-up period (mean \pm standard deviation, $34.4 \pm 2.3$ at baseline v. 21.3 \pm 6.2 at 24 months, $p<0.001)$. In addition, scores on the Hamilton Rating Scales for Depression (HAM-D) and Anxiety (HAM-A) also significantly decreased from baseline over the 24-month period (HAM-D, $19.0 \pm 5.3$ v. $7.6 \pm 5.3$, $p<0.001$; HAM-A, $22.4 \pm 5.9$ v. $7.9 \pm 3.9, p<0.001)$. The Global Assessment of Functioning (GAF) scores improved significantly $(35.8 \pm 4.9$ at baseline v. $56.0 \pm 10.3$ at 24 months, $p<0.001)$. Other neuropsychological function test scores, such as Wechsler Adult Intelligence Scale-Korean version 


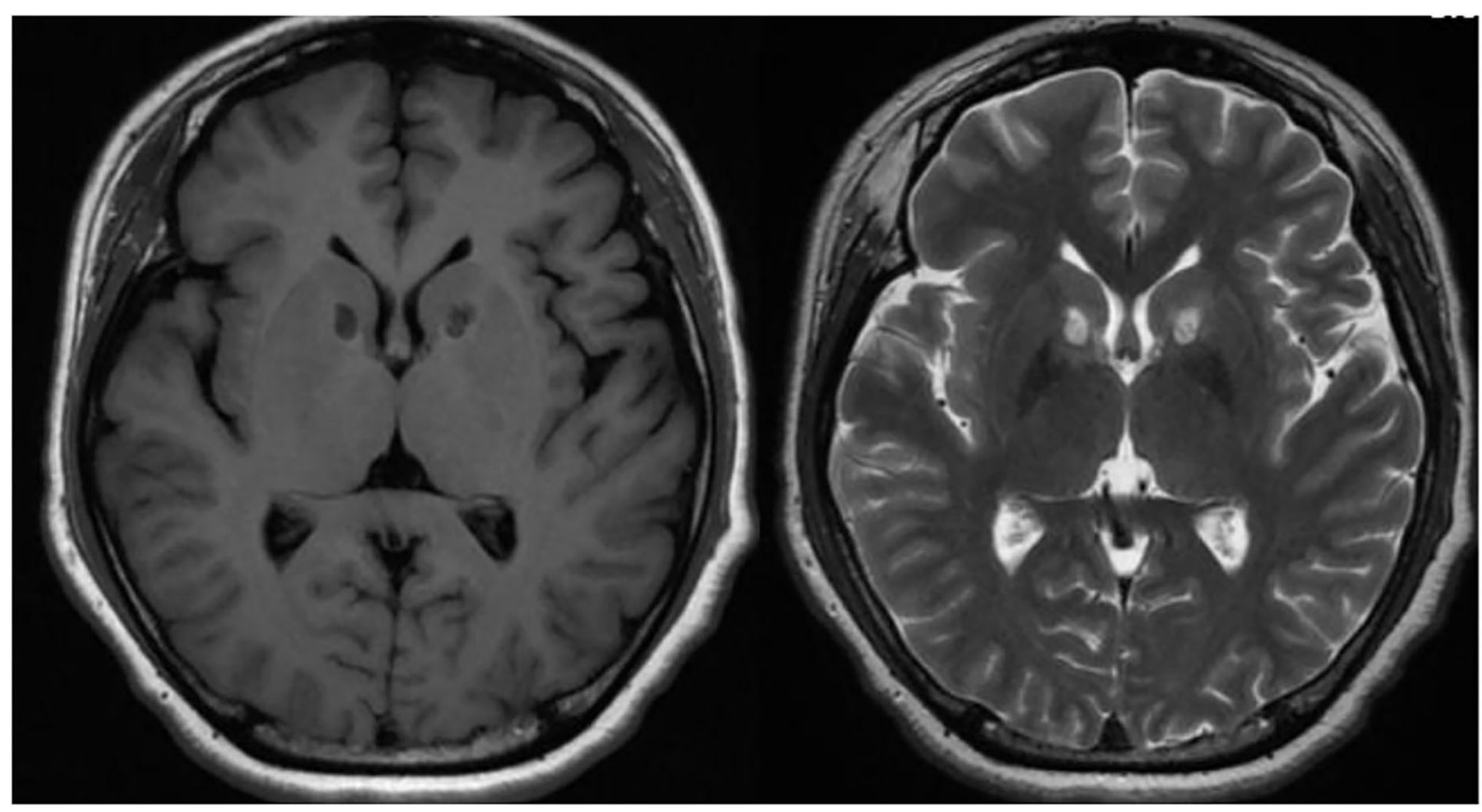

FIGURE 1 | One-week post-operative MR image of a patient with MRgFUS Capsulotomy.

scores, Memory Quotient scores, and Digit Span test-forward scores, were significantly improved, while other test scores, such as the Controlled Oral Word Association test scores, Stroop test scores, and Digit Span test-backward scores, remained unchanged. Compared to the pre-sonication condition, highresolution fluorodeoxyglucose positron emission tomography of the eight patients showed significantly decreased uptake in the orbitofrontal cortex $(p<0.001)$. The side effects of MRgFUS included headache and vestibular symptoms, but these were mild and temporary. Thus, these findings showed that bilateral thermal lesioning of the ALIC using MRgFUS may improve obsessive-compulsive, depressive, and anxiety symptoms in patients with treatment-refractory OCD, without serious side effects.

In our very recent study (77), we successfully performed bilateral thermal capsulotomy with MRgFUS in four patients with treatment-resistant depression (TRD). All patients underwent MRgFUS without serious side effects. During the 12-month follow-up period, all four patients experienced reduced symptoms and improved functional scores: the Beck Depression Inventory and Hamilton Depression Scale (HAM-D) scores decreased by 61.2 and $83.0 \%$, respectively, and the GAF total score improved by more than $50 \%$. Our results were consistent with those of TRD patients who underwent conventional radiofrequency capsulotomy, although we observed faster improvement in our patients. Three of the four patients experienced a faster decrease in symptoms within 1 week of MRgFUS, which may be due to postprocedure anxiety relief. In addition, all participants were able to continue their daily activities from the day after the procedure, without complications. These results suggest the possibility that capsulotomy by MRgFUS can also improve various psychiatric disorders.

In a recent study by Davidson et al. (78). MRgFUS capsulotomy was performed in 12 patients (six patients with OCD and six patients with MDD) without serious clinical or radiographic adverse events. For OCD, a 35\% reduction in the Yale-Brown Obsessive-Compulsive Scale and for MDD, a 50\% reduction in the 17-item Hamilton Depression Rating Scale was observed.

However, as research is still insufficient, in order not to repeat the mistakes of the previous history of psychiatric neurosurgery, it is important to conduct research on MRgFUS capsulotomy only in institutions with teams of well-experienced functional neurosurgeons and psychiatrists.

To date, the application of MRgFUS for numerous brain targets for treating psychiatric disorders has been limited $(29,76)$ in patients with a low skull-density ratio (which represents a skull that is difficult to penetrate by ultrasound) and with lateral targets (on which it is difficult to focus ultrasound). Nevertheless, ongoing technical development may eventually overcome these limitations.

\section{CONCLUSION}

Among the currently available surgical techniques, MRgFUS is emerging as a promising ablative surgical method. Further larger cohort studies are required to compare the surgical methods in future. 


\section{AUTHOR CONTRIBUTIONS}

KC wrote the paper. HJ and JC provided the idea and reviewed the paper. All authors contributed to the article and approved the submitted version.

\section{FUNDING}

This study was supported by a grant of the Korea Health Technology R\&D Project through the Korea Health

\section{REFERENCES}

1. Stein DJ, Costa DLC, Lochner C, Miguel EC, Reddy YCJ, Shavitt RG, et al. Obsessive-compulsive disorder. Nat Rev Disease Primers. (2019) 5:52. doi: 10.1038/s41572-019-0102-3

2. Pinto A, Mancebo MC, Eisen JL, Pagano ME, Rasmussen SA. The brown longitudinal obsessive compulsive study: clinical features and symptoms of the sample at intake. J Clin Psychiatry. (2006) 67:70311. doi: 10.4088/JCP.v67n0503

3. Subramaniam M, Soh P, Vaingankar JA, Picco L, Chong SA. Quality of life in obsessive-compulsive disorder: impact of the disorder and of treatment. CNS Drugs. (2013) 27:367-83. doi: 10.1007/s40263-013-0056-Z

4. Ramos-Cerqueira AT, Torres AR, Torresan RC, Negreiros AP, Vitorino $\mathrm{CN}$. Emotional burden in caregivers of patients with obsessive-compulsive disorder. Depress Anxiety. (2008) 25:1020-7. doi: 10.1002/da.20431

5. Hirschtritt ME, Bloch $\mathrm{MH}$, Mathews CA. Obsessive-compulsive disorder. JAMA. (2017) 317:1358-67. doi: 10.1001/jama.2017.2200

6. Dell'Osso B, Camuri G, Benatti B, Buoli M, Altamura AC. Differences in latency to first pharmacological treatment (duration of untreated illness) in anxiety disorders: a study on patients with panic disorder, generalized anxiety disorder and obsessive-compulsive disorder. Early Interv Psychiatry. (2013) 7:374-80. doi: 10.1111/eip.12016

7. Torres AR, Prince MJ, Bebbington PE, Bhugra DK, Brugha TS, Farrell M, et al. Treatment seeking by individuals with obsessive-compulsive disorder from the british psychiatric morbidity survey of (2000). Psychiatr Serv. (2007) 58:977-82. doi: 10.1176/ps.2007.58.7.977

8. Skapinakis P, Caldwell DM, Hollingworth W, Bryden P, Fineberg NA, Salkovskis P, et al. Pharmacological and psychotherapeutic interventions for management of obsessive-compulsive disorder in adults: a systematic review and network meta-analysis. Lancet Psychiatry. (2016) 3:7309. doi: 10.1016/S2215-0366(16)30069-4

9. Soomro GM, Altman D, Rajagopal S, Oakley-Browne M. Selective serotonin re-uptake inhibitors (SSRIs) versus placebo for obsessive compulsive disorder (OCD). Cochrane Database Syst Rev. (2008) 2008:CD001765. doi: 10.1002/14651858.CD001765.pub3

10. Pallanti S, Quercioli L. Treatment-refractory obsessive-compulsive disorder: methodological issues, operational definitions and therapeutic lines. Prog Neuropsychopharmacol Biol Psychiatry. (2006) 30:400-12. doi: 10.1016/j.pnpbp.2005.11.028

11. Nuttin B, Wu H, Mayberg H, Hariz M, Gabriels L, Galert T, et al. Consensus on guidelines for stereotactic neurosurgery for psychiatric disorders. J Neurol Neurosurg Psychiatry. (2014) 85:1003-8. doi: 10.1136/jnnp-2013-306580

12. Greenberg BD, Rauch SL, Haber SN. Invasive circuitry-based neurotherapeutics: stereotactic ablation and deep brain stimulation for OCD. Neuropsychopharmacology. (2010) 35:317-36. doi: 10.1038/npp. 2009.128

13. Alonso P, Cuadras D, Gabriels L, Denys D, Goodman W, Greenberg BD, et al. Deep brain stimulation for obsessive-compulsive disorder: a metaanalysis of treatment outcome and predictors of response. PLOS ONE. (2015) 10:e133591. doi: 10.1371/journal.pone.0133591

14. Staudt MD, Herring EZ, Gao K, Miller JP, Sweet JA. Evolution in the treatment of psychiatric disorders: from psychosurgery to psychopharmacology to neuromodulation. Front Neurosci. (2019) 13:108. doi: 10.3389/fnins.2019.00108
Industry Development Institute (KHIDI), funded by the Ministry of Health and Welfare, Republic of Korea (Grant No. HI19C0060).

\section{ACKNOWLEDGMENTS}

This is a short text to acknowledge the contributions of specific colleagues, institutions, or agencies that aided the efforts of the authors.

15. Simpson D. Phrenology and the neurosciences: contributions of F. J. Gall and J. G. Spurzheim. ANZ J Surg. (2005) 75:47582. doi: 10.1111/j.1445-2197.2005.03426.x

16. Robison RA, Taghva A, Liu CY, Apuzzo ML. Surgery of the mind, mood, and conscious state: an idea in evolution. World Neurosurg. (2013) 80:S226. doi: 10.1016/j.wneu.2013.08.002

17. Luigjes J, de Kwaasteniet BP, de Koning PP, Oudijn MS, van den Munckhof P, Schuurman PR, et al. Surgery for psychiatric disorders. World Neurosurgery. (2013) 80:S31.e17-S31.e28. doi: 10.1016/j.wneu.2012.03.009

18. Moniz E. Prefrontal leucotomy in the treatment of mental disorders 1937. Am J Psychiatry. (1994). 151(6 Suppl):236-9. doi: 10.1176/ajp.151.6.236

19. Gross D, Schafer G. Egas Moniz (1874-1955) and the "invention" of modern psychosurgery: a historical and ethical reanalysis under special consideration of Portuguese original sources. Neurosurg Focus. (2011) 30:E8. doi: 10.3171/2010.10.FOCUS10214

20. Heller AC, Amar AP, Liu CY, Apuzzo ML. Surgery of the mind and mood: a mosaic of issues in time and evolution. Neurosurgery. (2008) 62(6 Suppl 3):921-40. doi: 10.1227/01.NEU.0000333761.30877.8D

21. Leiphart JW, Valone FH 3rd. Stereotactic lesions for the treatment of psychiatric disorders. J Neurosurg. (2010) 113:120411. doi: 10.3171/2010.5.JNS091277

22. Feldman RP, Goodrich JT. Psychosurgery: a historical overview. Neurosurgery. (2001) 48:647-57; discussion 57-9. doi: 10.1097/00006123-200103000-00041

23. Ballantine HT, Jr. Historical overview of psychosurgery and its problematic. Acta Neurochir Suppl (Wien). (1988) 44:1258. doi: 10.1007/978-3-7091-9005-0_25

24. Levine RJ. Recommendations of the national commission for the protection of human subjects of biomedical and behavioral research: impact on research in pharmacology. Introduction Fed Proc. (1977) 36:2341-3.

25. Sinha S, McGovern RA, Mikell CB, Banks GP, Sheth SA. Ablative limbic system surgery: review and future directions. Curr Behav Neurosci Rep. (2015) 2:49-59. doi: 10.1007/s40473-015-0038-1

26. Kumar KK, Bhati MT, Ravikumar VK, Ghanouni P, Stein SC, Halpern $\mathrm{CH}$. MR-guided focused ultrasound versus radiofrequency capsulotomy for treatment-refractory obsessive-compulsive disorder: a cost-effectiveness threshold analysis. Front Neurosci. (2019) 13:66. doi: 10.3389/fnins.2019.00066

27. Jung HH, Kim SJ, Roh D, Chang JG, Chang WS, Kweon EJ, et al. Bilateral thermal capsulotomy with MR-guided focused ultrasound for patients with treatment-refractory obsessive-compulsive disorder: a proofof-concept study. Mol Psychiatry. (2014) 20:1205-11. doi: 10.1038/mp. 2014.154

28. Jung HH, Kim C-H, Chang JH, Park YG, Chung SS, Chang JW. Bilateral anterior cingulotomy for refractory obsessive-compulsive disorder: longterm follow-up results. Stereotactic Functional Neurosurgery. (2006) 84:1849. doi: 10.1159/000095031

29. Jung HH, Chang WS, Kim SJ, Kim C-H, Chang JW. The potential usefulness of magnetic resonance guided focused ultrasound for obsessive compulsive disorders. J Korean Neurosurg Soc. (2018) 61:427-33. doi: 10.3340/jkns.2017.0505.004

30. Kim SJ, Roh D, Jung HH, Chang WS, Kim C-H, Chang JW. A study of novel bilateral thermal capsulotomy with focused ultrasound for treatmentrefractory obsessive-compulsive disorder: 2-year follow-up. J Psychiatry Neurosci. (2018) 43:327-37. doi: 10.1503/jpn.170188 
31. Lopes AC, Greenberg BD, Canteras MM, Batistuzzo MC, Hoexter MQ, Gentil AF, et al. Gamma ventral capsulotomy for obsessive-compulsive disorder: a randomized clinical trial. JAMA Psychiatry. (2014) 71:106676. doi: 10.1001/jamapsychiatry.2014.1193

32. Ballantine HT Jr, Cassidy WL, Flanagan NB, Marino R Jr. Stereotaxic anterior cingulotomy for neuropsychiatric illness and intractable pain. J Neurosurg. (1967) 26:488-95. doi: 10.3171/jns.1967.26.5.0488

33. Scoville WB. Selective cortical undercutting as a means of modifying and studying frontal lobe function in man; preliminary report of 43 operative cases. J Neurosurg. (1949) 6:65-73. doi: 10.3171/jns.1949.6.1.0065

34. Dunsmore RH, Lennox MA. Stimulation and strychninization of supracallosal anterior cingulate gyrus. J Neurophysiol. (1950) 13:207-14. doi: 10.1152/jn.1950.13.3.207

35. Whitty CW, Duffield JE, Tov PM, Cairns H. Anterior cingulectomy in the treatment of mental disease. Lancet. (1952) 1:47581. doi: 10.1016/S0140-6736(52)90051-2

36. Foltz EL, White LE Jr. Pain "relief" by frontal cingulumotomy. J Neurosurg. (1962) 19:89-100. doi: 10.3171/jns.1962.19.2.0089

37. Laitinen L, Toivakka E, Vilkki I. [Rostral cingulotomy for mental disorders (electrophysiologic, psychological and clinical findings)]. Vopr Neirokhir. (1973) 37:23-30.

38. Hassenbusch SJ, Pillay PK, Barnett GH. Radiofrequency cingulotomy for intractable cancer pain using stereotaxis guided by magnetic resonance imaging. Neurosurgery. (1990) 27:2203. doi: 10.1227/00006123-199008000-00008

39. Ballantine HT Jr, Bouckoms AJ, Thomas EK, Giriunas IE. Treatment of psychiatric illness by stereotactic cingulotomy. Biol Psychiatry. (1987) 22:80719. doi: 10.1016/0006-3223(87)90080-1

40. Brown LT, Mikell CB, Youngerman BE, Zhang Y, McKhann GM, 2nd, Sheth SA. Dorsal anterior cingulotomy and anterior capsulotomy for severe, refractory obsessive-compulsive disorder: a systematic review of observational studies. J Neurosurg. (2016) 124:77-89. doi: 10.3171/2015.1.JNS14681

41. Kim CH, Chang JW, Koo MS, Kim JW, Suh HS, Park IH, et al. Anterior cingulotomy for refractory obsessive-compulsive disorder. Acta Psychiatr Scand. (2003) 107:283-90. doi: 10.1034/j.1600-0447.2003.00087.x

42. Sheth SA, Neal J, Tangherlini F, Mian MK, Gentil A, Cosgrove GR, et al. Limbic system surgery for treatment-refractory obsessive-compulsive disorder: a prospective long-term follow-up of 64 patients. J Neurosurg. (2013) 118:4917. doi: 10.3171/2012.11.JNS12389

43. Leksell L. Stereotactic radiosurgery. J Neurol Neurosurg Psychiatry. (1983) 46:797-803. doi: 10.1136/jnnp.46.9.797

44. Leveque M, Carron R, Regis J. Radiosurgery for the treatment of psychiatric disorders: a review. World Neurosurg. (2013) 80:S32 e19. doi: 10.1016/j.wneu.2013.07.004

45. Lippitz B, Mindus P, Meyerson BA, Kihlstrom L, Lindquist C. Obsessive compulsive disorder and the right hemisphere: topographic analysis of lesions after anterior capsulotomy performed with thermocoagulation. Acta Neurochir Suppl. (1997) 68:61-3. doi: 10.1007/978-3-7091-6513-3_11

46. Oliver B, Gascon J, Aparicio A, Ayats E, Rodriguez R, Maestro De Leon JL, et al. Bilateral anterior capsulotomy for refractory obsessive-compulsive disorders. Stereotact Funct Neurosurg. (2003) 81:90-5. doi: 10.1159/0000 75110

47. Liu K, Zhang H, Liu C, Guan Y, Lang L, Cheng Y, et al. Stereotactic treatment of refractory obsessive compulsive disorder by bilateral capsulotomy with 3 years follow-up. J Clin Neurosci. (2008) 15:622-9. doi: 10.1016/j.jocn.2007.07.086

48. D'Astous M, Cottin S, Roy M, Picard C, Cantin L. Bilateral stereotactic anterior capsulotomy for obsessive-compulsive disorder: long-term follow-up. J Neurol Neurosurg Psychiatry. (2013) 84:1208-13. doi: 10.1136/jnnp-2012-303826

49. Ruck C, Karlsson A, Steele JD, Edman G, Meyerson BA, Ericson $\mathrm{K}$, et al. Capsulotomy for obsessive-compulsive disorder: longterm follow-up of 25 patients. Arch Gen Psychiatry. (2008) 65:914-21. doi: 10.1001/archpsyc.65.8.914

50. Kihlstrom L, Hindmarsh T, Lax I, Lippitz B, Mindus P, Lindquist C. Radiosurgical lesions in the normal human brain 17 years after gamma knife capsulotomy. Neurosurgery. (1997) 41:396-401; discussion -2. doi: 10.1097/00006123-199708000-00011
51. Kondziolka D, Flickinger JC, Hudak R. Results following gamma knife radiosurgical anterior capsulotomies for obsessive compulsive disorder. Neurosurgery. (2011) 68:28-32; discussion 23-3. doi: 10.1227/NEU.0b013e3181fc5c8b

52. Rasmussen SA, Noren G, Greenberg BD, Marsland R, McLaughlin NC, Malloy PJ, et al. Gamma ventral capsulotomy in intractable obsessive-compulsive disorder. Biol Psychiatry. (2018) 84:35564. doi: 10.1016/j.biopsych.2017.11.034

53. Miguel EC, Lopes AC, McLaughlin NCR, Noren G, Gentil AF, Hamani C, et al. Evolution of gamma knife capsulotomy for intractable obsessive-compulsive disorder. Mol Psychiatry. (2019) 24:218-40. doi: 10.1038/s41380-018-0054-0

54. Kelly D, Richardson A, Mitchell-Heggs N. Stereotactic limbic leucotomy: neurophysiological aspects and operative technique. Br J Psychiatry. (1973) 123:133-40. doi: 10.1192/bjp.123.2.133

55. Mashour GA, Walker EE, Martuza RL. Psychosurgery: past, present, and future. Brain Res Brain Res Rev. (2005) 48:40919. doi: 10.1016/j.brainresrev.2004.09.002

56. Bourne SK, Sheth SA, Neal J, Strong C, Mian MK, Cosgrove GR, et al. Beneficial effect of subsequent lesion procedures after nonresponse to initial cingulotomy for severe, treatment-refractory obsessive-compulsive disorder. Neurosurgery. (2013) 72:196-202; discussion doi: 10.1227/NEU.0b013e31827b9c7c

57. Cho DY, Lee WY, Chen CC. Limbic leukotomy for intractable major affective disorders: a 7-year follow-up study using nine comprehensive psychiatric test evaluations. J Clin Neurosci. (2008) 15:138-42. doi: 10.1016/j.jocn. 2006.10.017

58. Lujan JL, Chaturvedi A, McIntyre CC. Tracking the mechanisms of deep brain stimulation for neuropsychiatric disorders. Front Biosci. (2008) 13:5892904. doi: $10.2741 / 3124$

59. Bear RE, Fitzgerald P, Rosenfeld JV, Bittar RG. Neurosurgery for obsessivecompulsive disorder: contemporary approaches. J Clin Neurosci. (2010) 17:15. doi: 10.1016/j.jocn.2009.02.043

60. Garnaat SL, Greenberg BD, Sibrava NJ, Goodman WK, Mancebo MC, Eisen JL, et al. Who qualifies for deep brain stimulation for OCD? Data from a naturalistic clinical sample. J Neuropsychiatry Clin Neurosci. (2014) 26:816. doi: 10.1176/appi.neuropsych.12090226

61. Hamani C, Pilitsis J, Rughani AI, Rosenow JM, Patil PG, Slavin KS, et al. Deep brain stimulation for obsessive-compulsive disorder: systematic review and evidence-based guideline sponsored by the American Society for Stereotactic and Functional Neurosurgery and the Congress of Neurological Surgeons (CNS) and endorsed by the CNS and American Association of Neurological Surgeons. Neurosurgery. (2014) 75:327-33; quiz 33. doi: 10.1227/NEU.0000000000000499

62. Sturm V, Lenartz D, Koulousakis A, Treuer H, Herholz K, Klein JC, et al. The nucleus accumbens: a target for deep brain stimulation in obsessivecompulsive- and anxiety-disorders. J Chem Neuroanat. (2003) 26:2939. doi: 10.1016/j.jchemneu.2003.09.003

63. Chang WS, Roh D, Kim CH, Chang JW. Combined bilateral anterior cingulotomy and ventral capsule/ventral striatum deep brain stimulation for refractory obsessive-compulsive disorder with major depression: do combined procedures have a long-term benefit? Restor Neurol Neurosci. (2013) 31:72332. doi: $10.3233 / \mathrm{RNN}-120290$

64. Coenen VA, Schlaepfer TE, Goll P, Reinacher PC, Voderholzer U, Tebartz van Elst L, et al. The medial forebrain bundle as a target for deep brain stimulation for obsessive-compulsive disorder. CNS Spectr. (2017) 22:2829. doi: $10.1017 /$ S1092852916000286

65. Nuttin BJ, Gabriels L, van Kuyck K, Cosyns P. Electrical stimulation of the anterior limbs of the internal capsules in patients with severe obsessivecompulsive disorder: anecdotal reports. Neurosurg Clin N Am. (2003) 14:26774. doi: 10.1016/S1042-3680(02)00117-1

66. van Kuyck K, Brak K, Das J, Rizopoulos D, Nuttin B. Comparative study of the effects of electrical stimulation in the nucleus accumbens, the mediodorsal thalamic nucleus and the bed nucleus of the stria terminalis in rats with schedule-induced polydipsia. Brain Res. (2008) 1201:939. doi: 10.1016/j.brainres.2008.01.043

67. Jimenez-Ponce F, Velasco-Campos F, Castro-Farfan G, Nicolini H, Velasco AL, Salin-Pascual R, et al. Preliminary study in patients with obsessivecompulsive disorder treated with electrical stimulation in the inferior 
thalamic peduncle. Neurosurgery. (2009) 65(6 Suppl):203-9; discussion 9. doi: 10.1227/01.NEU.0000345938.39199.90

68. Greenberg BD, Malone DA, Friehs GM, Rezai AR, Kubu CS, Malloy PF, et al. Three-year outcomes in deep brain stimulation for highly resistant obsessive-compulsive disorder. Neuropsychopharmacology. (2006) 31:238493. doi: 10.1038/sj.npp. 1301165

69. Denys D, Mantione M, Figee M, van den Munckhof P, Koerselman F, Westenberg H, et al. Deep brain stimulation of the nucleus accumbens for treatment-refractory obsessive-compulsive disorder. Arch Gen Psychiatry. (2010) 67:1061-8. doi: 10.1001/archgenpsychiatry.2010.122

70. Mallet L, Polosan M, Jaafari N, Baup N, Welter ML, Fontaine D, et al. Subthalamic nucleus stimulation in severe obsessive-compulsive disorder. $N$ Engl J Med. (2008) 359:2121-34. doi: 10.1056/NEJMoa0708514

71. Videnovic A, Metman LV. Deep brain stimulation for Parkinson's disease: prevalence of adverse events and need for standardized reporting. Mov Disord. (2008) 23:343-9. doi: 10.1002/mds.21753

72. Fry WJ, Barnard JW, Fry FJ, Brennan JF. Ultrasonically produced localized selective lesions in the central nervous system. Am J Phys Med. (1955) 34:413-23.

73. Fry WJ. Intense ultrasound in investigations of the central nervous system. Adv Biol Med Phys. (1958) 6:281348. doi: 10.1016/B978-1-4832-3112-9.50012-8

74. Chang KW, Park YS, Chang JW. Skull factors affecting outcomes of magnetic resonance-guided focused ultrasound for patients with essential tremor. Yonsei Med J. (2019) 60:768-73. doi: 10.3349/ymj.2019.60.8.768

75. Kyriakou A, Neufeld E, Werner B, Paulides MM, Szekely G, Kuster N. A review of numerical and experimental compensation techniques for skull-induced phase aberrations in transcranial focused ultrasound. Int $J$ Hyperthermia. (2014) 30:36-46. doi: 10.3109/02656736.2013.861519

76. Giordano M, Caccavella VM, Zaed I, Foglia Manzillo L, Montano N, Olivi A, et al. Comparison between deep brain stimulation and magnetic resonanceguided focused ultrasound in the treatment of essential tremor: a systematic review and pooled analysis of functional outcomes. J Neurol Neurosurg Psychiatry. (2020) 91:1270-8. doi: 10.1136/jnnp-2020-323216

77. Chang Jg, Jung HH, Kim SJ, Chang WS, Jung NY, Kim $\mathrm{CH}$, et al. Bilateral thermal capsulotomy with magnetic resonance-guided focused ultrasound for patients with treatment-resistant depression: a proofof-concept study. Bipolar Disorders. (2020) 22:771-4. doi: 10.1111/ bdi. 12964

78. Davidson B, Hamani C, Huang Y, Jones RM, Meng Y, Giacobbe P, et al. Magnetic resonance-guided focused ultrasound capsulotomy for treatment-resistant psychiatric disorders. Operative Neurosurgery. (2020). doi: 10.1093/ons/opaa240. [Epub ahead of print].

Conflict of Interest: The authors declare that the research was conducted in the absence of any commercial or financial relationships that could be construed as a potential conflict of interest.

Copyright $\odot 2021$ Chang, Jung and Chang. This is an open-access article distributed under the terms of the Creative Commons Attribution License (CC BY). The use, distribution or reproduction in other forums is permitted, provided the original author(s) and the copyright owner(s) are credited and that the original publication in this journal is cited, in accordance with accepted academic practice. No use, distribution or reproduction is permitted which does not comply with these terms. 